\title{
Sputum Smears Conversion in Daily Versus Intermittent Treatment Regimen in New Sputum Smear Positive Pulmonary Tuberculosis Patients - A Retrospective Study
}

\author{
Dhondiba Haribhau Bhise ${ }^{1}$ \\ ${ }^{1}$ Department of Respiratory Medicine, Government Medical College, Akola, Maharashtra, India.
}

\section{ABSTRACT}

\section{BACKGROUND}

Sputum smear conversion is the negative conversion of the sputum smear at the end of the second month of treatment regimen under the National Tuberculosis Elimination Program (NTEP). When the acid-fast bacillus (AFB) smear comes negative at the end of an intensive phase, the treatment regimen can shift to the continuation phase that indicates bacillary load is a minimum. Although some authors consider the conversion of cultures when the AFB smear is negative, two potent drugs in the continuation phase are sufficient to kill the remaining bacilli. The drug that can kill bacteria in the first 2 days of treatment is called early bactericidal activity (EBA). This can be assessed by the percentage of negative conversion of cultures at the end of the intensive phase of the treatment regimen. EBA is very essential because it reduces the transmission in the community and chances of patient death. When the purpose is to kill as many bacilli as possible in the first few days and weeks of treatment, it is very important to include bactericidal drugs in the treatment regimen so that it reduces the chances of patient death and infectiousness and the negative conversion of the cultures after 2-month treatment regimen is an indication of the bactericidal capacity of the drug. The purpose of this study was to compare sputum smear conversion in daily versus intermittent treatment regimens in diagnosed cases of new sputum smear-positive pulmonary tuberculosis patients.

\section{METHODS}

This retrospective observational study was carried out in the Department of Respiratory medicine and nodal drug resistance tuberculosis centre (DR-TB) at the Government medical college and hospital, Akola. In this study, a total of 120 new patients were taken. 60 patients were given daily and intermittent regimens respectively under NTEP.

\section{RESULTS}

Out of 120 patients, 56 (93.33\%) patients in intermittent and 53 (88.33\%) patients in daily regimen were sputum smear-negative at the end of 2 nd month (intensive phase) and at the end of 6th month (continuation phase). 1 patient (1.6\%) remained sputum smear-positive after the intensive phase. That patient was given 1 month of extension of anti-tuberculosis treatment (AKT) in the intensive phase and the patient became sputum negative after 1 month of extension.

\section{CONCLUSIONS}

It was concluded in this study, daily regimens and intermittent regimens were equally effective in negative conversion of the sputum smear at the end of the intensive phase and the end of the continuation phase. Negative conversion of the sputum smear is quite important because the bacillary load will be so low the end of $2^{\text {nd }}$ month that reduces the chances of patient death and transmission in the community.

\section{KEY WORDS}

Pulmonary Tuberculosis (PTB), Drug-Resistant TB (DR-TB), National Tuberculosis Programme (NTP), Revised National TB Control Program (RNTCP), Intensive Phase (IP), continuation Phase (CP), National Tuberculosis Elimination Program (NTEP).
Corresponding Author: Dr. Dhondiba Haribhau Bhise, Room No. 202, Second Floor, Bella Vista Apartment, Near Dube STD, Geeta Nagar, Akoli, Br., Akola-444001, Maharashtra, India.

E-mail: bhisedhondiba@gmail.com

DOI: $10.14260 / j e m d s / 2021 / 734$

How to Cite This Article:

Bhise DH. Sputum smears conversation in daily verses intermittent treatment regimen in new sputum smear positive pulmonary tuberculosis patients - a retrospective study. J Evolution Med Dent Sci 2021;10(42):3617-3622, DOI: $10.14260 /$ jemds $/ 2021 / 734$

Submission 20-08-2021,

Peer Review 30-09-2021,

Acceptance 07-10-2021,

Published 18-10-2021.

Copyright (C) 2021 Dhondiba Haribhau Bhise et al. This is an open access article distributed under Creative Commons Attribution License [Attribution 4.0 International (CC BY 4.0)] 


\section{BACKGROUND}

Pulmonary tuberculosis (PTB) is a chronic infectious disease caused by Mycobacterium tuberculosis. Tuberculosis (TB) was called "phthisis" in ancient Greece, "tabes" in ancient Rome, and "schachepheth" in ancient Hebrew. In the 1700s, TB was called "the white plague" due to the paleness of the patients. In 1720 he conjectured in "A New Theory of Consumptions More Especially a Phthisis or Consumption of the Lungs", that tuberculosis may be caused by "wonderfully minute living creatures" that could lead to the lesions symptomatic of the disease, thereby expressing the theory of contagium vivum or 'living contagion.' 1 TB was commonly called "consumption" in the 1800s. Johann Schonlein coined the term "tuberculosis" in 1834. René Théophile Hyacinthe Laennec suffered from this disease while studying tuberculosis and he died in $1826 . .^{2} \mathrm{~A}$ sanatorium is a medical facility for the treatment of tuberculosis (TB). The discovery of Mycobacterium tuberculosis was announced by Dr Robert Koch on March 24, 1882. A century later, March 24 was designated as World TB Day. On this day people educate about tuberculosis and its impact. ${ }^{3}$ Patients who are having cavities in their lungs are sputum smear-positive patients and these patients are highly infectious. When these patients cough out produces tiny infectious droplets nuclei. These infectious droplets nuclei remain in the air for a prolonged period of time, and also remain in cold as they are killed by direct exposure to sunlight and removed by ventilation. And when a person has a cavity or a patient is not treated for tuberculosis these patients when cough out these droplet nuclei containing $M$. tuberculosis when inhaled by another person gets transmitted and nuclei reaches the alveoli of the lungs through the respiratory passage. ${ }^{4}$ The risk of transmission of infection from a person with sputum smear-negative pulmonary tuberculosis is very low and person with miliary tuberculosis, extrapulmonary tuberculosis is negligible. Of the several factors, two important factors determining an individual risk of exposure include the concentration of droplet nuclei in contaminated air and the period of time that air is breathed. ${ }^{5}$ Third important factor is host immunity. After the assumption of tuberculosis (TB) becoming a curable illness in all cases, data was showing that the emergence of resistance of Mycobacterium tuberculosis strains to the most of used active existing drugs has once again made significant menace to global public health. The first important message must be sent to everyone that every form of drug resistance tuberculosis including a very extensive pattern of drug resistance is treatable and curable with good clinical and operational case management, 6 the chances for success are increased with good management and it also depends on the patient's patterns of resistance. The National Tuberculosis Programme (NTP) was launched by the Government of India in 1962 and The Revised National TB Control Program (RNTCP) was started in 1997. In India before 2017, treatment of tuberculosis was thrice a week, on alternate-days. Treatment is given as the intensive phase for 2 months (24 doses) and continuation phase for 4 months (54 doses). Total duration of the treatment regimen is for 6 months. The intensive phase consists of 4 drugs that are isoniazid, rifampicin, ethambutol and pyrazinamide thrice a week on alternate days given under direct observation. And continuation phase consists of 2 drugs isoniazid and rifampicin given on alternate days thrice a week with the first dose every week being directly observed. ${ }^{7}$ In 2020, the programme was renamed from 'Revised National Tuberculosis Control Program (RNTCP) to 'National Tuberculosis Elimination Program (NTEP) given End TB targets. Daily fixed-dose combination treatment for tuberculosis started in India in the year 2017. The principle of treatment for susceptible tuberculosis in NTEP is to give daily fixed-dose combinations of first-line anti-tuberculosis drugs in appropriate weight bands. The total duration of treatment is of 6 months. Intensive phase (IP) of 2 months and a Continuation phase (CP) of 4 months. Intensive phase (IP) includes isoniazid (H), rifampicin (R), ethambutol (E), and pyrazinamide (Z) of 56 doses given under direct observation in daily dosages as per weight band. The continuation phase (CP), includes isoniazid, rifampicin and ethambutol of 112 doses in daily dosages. Pyrazinamide will be stopped in the continuation phase. In certain forms of TB like CNS TB, Skeletal TB, Disseminated TB the CP may be extended by $12-24$ weeks on case to case basis. ${ }^{8}$

The purpose of this study was to compare sputum smear conversion in daily versus intermittent treatment regimens in diagnosed cases of new sputum smear-positive pulmonary tuberculosis patients.

\section{METHODS}

A total of 120 new sputum smear-positive patients were randomly selected in the present study after written informed consent was taken from these patients. These patients were referred to tertiary care hospitals for diagnosis and treatment of tuberculosis. This retrospective observational study was conducted in the Department of Respiratory medicine and nodal drug resistance tuberculosis centre (DR-TB) at a Government medical college and hospital, Akola from June 2020 to June 2021. Ethical clearance was taken from the ethical committee of the institution. Detailed clinical history of all new suspected patients of pulmonary tuberculosis was taken from those who visited respiratory medicine OPD with symptoms like low-grade fever, cough equal to or more than 2 weeks, dyspnea, chest pain, weight loss and fatigue. History particularly that of tuberculosis and clinical examination of all patients were carried out. Investigations included sputum examination, X-ray chest PA view, random blood sugar level and human immunodeficiency virus (HIV) by enzyme-linked immunosorbent assay (ELISA). For sputum examination, all these suspected patients were sent to designated microscopy centres (DMC) at nodal DR-TB centre for Ziehl-Neelsen (ZN) staining. Instructions were given to the patients to collect the sputum in the container. With all necessary precautions, a specimen was collected on the spot, and for the second sample, all the suspected patients of pulmonary tuberculosis were then given another sputum container to collect an early morning sputum sample and other indicated investigations of these patients were done. After the diagnosis of patients as new sputum smear-positive pulmonary tuberculosis, these confirmed cases were included in this study. 


\section{Inclusion Criteria}

1. New sputum smear-positive patients.

2. Age equal to and more than 18 years.

\section{Exclusion Criteria}

1. Patients with smear-positive pulmonary tuberculosis defaulter.

2. Patients with smear-positive pulmonary tuberculosis failure.

3. Patients with smear-positive pulmonary tuberculosis relapse.

4. Severely ill, bedridden, moribund patients.

5. Co-morbid conditions like cerebrovascular disease, stroke, congestive heart failure, atrial fibrillation, renal disease.

There were two groups of newly diagnosed sputum smear-positive pulmonary tuberculosis patients. In the first group, they were administered daily fixed-dose combinations of first-line anti-tuberculosis drugs in appropriate weight bands that are isoniazid $(5 \mathrm{mg} / \mathrm{kg})$, rifampicin $(10 \mathrm{mg} / \mathrm{kg})$, ethambutol $(15 \mathrm{mg} / \mathrm{kg})$ and pyrazinamide $(25 \mathrm{mg} / \mathrm{kg})$ in the intensive phase and pyrazinamide was stopped in the continuation phase and continued with isoniazid $(5 \mathrm{mg} / \mathrm{kg}$ ) rifampicin $(10 \mathrm{mg} / \mathrm{kg})$ and ethambutol $(15 \mathrm{mg} / \mathrm{kg})$. In the second group, the treatment was given in two phases. The intensive phase consisted of two pills in a combi pack of isoniazid $(600 \mathrm{mg})$, one pill in a combi pack of rifampicin (450 mg), two pills in a combi pack of pyrazinamide (1500 $\mathrm{mg}$ ) and two pills in a combi pack of ethambutol (1200 mg) given in 24 doses for 2 months on alternate days thrice a week under direct observation. And in the continuation phase, 54 doses were given for 4 months of isoniazid and rifampicin on alternate days thrice a week with the first dose every week being directly observed. Patients were followed for the entire duration of treatment. Follow up included clinical assessment of patients, finding and management of the adverse effects of drugs and also addressing the adherence problems. Frequency of follow up done for every two months when the patient had medical problems. Patients were weighed at each visit and the doses were adjusted, if necessary. Sputum smear examination by Ziehl-Neelsen ( ZN ) staining was done for all patients at the end of the intensive phase that is at the end of the second month, at $4^{\text {th }}$ month and the end of $6^{\text {th }}$ month of treatment. The sputum conversion rate was compared at the $2^{\text {nd }}$ and the $6^{\text {th }}$ month of treatment.

\section{Statistical Significance}

All the data required for this study were collected and analysed statistically to compare sputum smear conversion in daily versus intermittent treatment regimens in diagnosed cases of new sputum smear-positive pulmonary tuberculosis patients using SPSS23. Hypothesis testing was conducted with parametric statistics. One-way ANOVA was a statistic. As a result, the null hypothesis was accepted under the entire hypothesis (P-value $>0.05$ ) at $95 \%$ of confidence.

\section{RESULTS}

This study compared sputum smear conversion in daily versus intermittent treatment regimens in new sputum smear-positive pulmonary tuberculosis patients. In the present study, there were a total of 120 patients. Out of 120 patients, 60 patients were initiated on daily antituberculosis treatment and 60 patients were initiated on intermittent antituberculosis treatment.

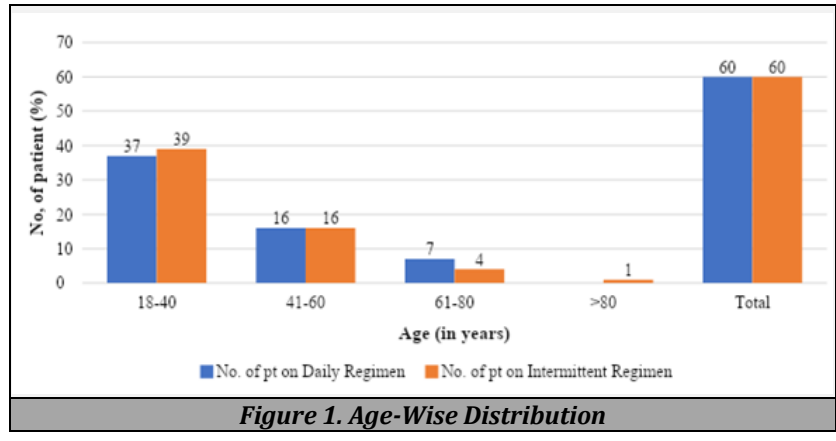

60 patients were randomly selected in each regimen. The majority of the patients with a total of $76(63.33 \%)$ belonged to 18 - 40 age group in daily as well as intermittent regimens, 37 patients $(61.7 \%)$ in daily and 39 patients $(65 \%)$ were present in the intermittent regimen. 16 patients $(26.7 \%)$ in the age group of $41-60$ were present in each treatment regimen. 7 patients $(11.7 \%)$ and 4 patients $(6.7 \%)$ in the age group of 61 - 80 years were present in daily and intermittent regimens respectively. Only 1 patient $(1.7 \%)$ in the age group of more than 80 years was present in an intermittent treatment regimen. Total 73 male patients were present in this study, 35 (58.3\%) males in daily and $38(63.3 \%)$ in intermittent regimen were present. Out of 47 (39.16\%) female patients, 25 (41.7\%) in daily and 22 (36.7\%) patients were present in the intermittent treatment regimen. 1 (1.7 $\%$ patient had resistance to isoniazid (high level), 3 patients (5\%) transferred out, 1 (1.7\%) patient was lost to follow up and $1(1.7 \%)$ patient was normal in daily regimen whereas no resistance, transferred out, lost to follow up and normal patients in an intermittent regimen. Whereas $3(5 \%)$ patients died and $1(1.7 \%)$ patient defaulted in intermittent regimen but no patient died or defaulted in daily regimen.

By null hypothesis there was no significant difference based on age in daily regimen and intermittent regimens, but there was a significant difference based on age in daily and intermittent regimens by alternative hypothesis. Parametric (ANOVA) test sum of squares - 6.933, df - 59 mean squares $0.115, \mathrm{~F}-1.587 \mathrm{P}$-value significant -0.213 in daily regimen and parametric (ANOVA) test sum of squares - 8.333, df - 59 mean squares - 0.144, F - 0.665, P-value significant - 0.577 in the intermittent regimen. Therefore, there was no difference in the results based on the age of the patient in daily regimen and intermittent regimen (Confidence interval $95 \%$ ).

73 (60.8\%) were male and 47 (39.1\%) were female patients with the majority being male patients in this study. Male to female ratio was 1.40 and 1.73 in daily and intermittent regimens respectively. There was no significant difference based on sex in daily regimen and intermittent regimen by null hypothesis but there was a significant 
difference based on sex in daily regimen and intermittent regimen by alternative hypothesis.

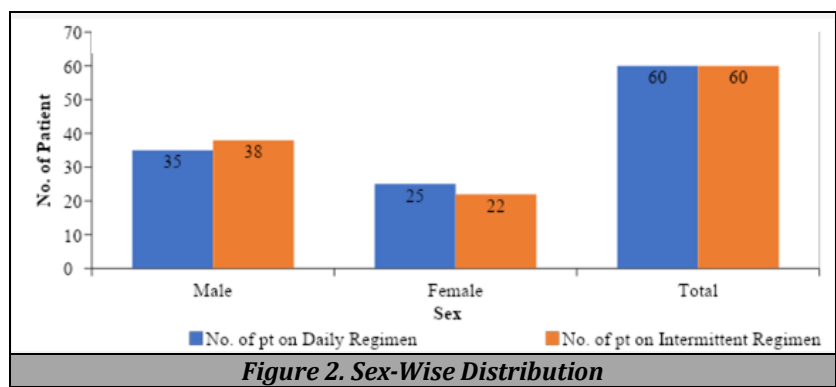

\begin{tabular}{|ccc|}
\hline $\begin{array}{c}\text { Outcomes } \\
\begin{array}{c}\text { Total No. of pt. sputum } \\
\text { conversion at 2 months }\end{array}\end{array}$ & $\begin{array}{c}\text { Total No. of pts in } \\
\text { Daily Regimen (\%) }\end{array}$ & $\begin{array}{c}\text { Total No. of pts in } \\
\text { Intermittent Regimen (\%) }\end{array}$ \\
$\begin{array}{c}\text { Total No. of pt. sputum } \\
\text { conversion at 6 months } \\
\text { No. of pt. developing } \\
\text { Resistance }\end{array}$ & $53.0(88.33)$ & $56.0(93.33)$ \\
$\begin{array}{c}\text { No. of pt. Transferred out } \\
\text { No. of pt. lost to F/u }\end{array}$ & $01.0(1.6 \%)$ & $56.0(93.33)$ \\
$\begin{array}{c}\text { No. of pt. not T/t (normal) } \\
\text { No. of pt. defaulted }\end{array}$ & $01.0(5.0 \%)$ & $00.0(0.0)$ \\
No. of pt. died & $01.0(1.6 \%)$ & $00.0(0.0)$ \\
Total & $00.0(0.0)$ & $03.0(5.0)$ \\
\multicolumn{2}{c}{ Table 1. Outcome wise distributions } \\
\hline \multicolumn{2}{c}{$60.0(100.0)$} \\
\hline
\end{tabular}

In daily regimen, parametric (ANOVA) test sum of squares 6.933, df-59, mean squares 0.119, $\mathrm{F}-0.256$, P-value significant - 0.615 and parametric (ANOVA) test sum of squares - 8.333, df-59 mean squares - 0.144, F - 0.056, Pvalue significant -0.814 in the intermittent regimen. Therefore, there was no difference in the results based on the sex of the patient in daily regimen and intermittent regimen (Confidence interval $95 \%$ ).

\begin{tabular}{|c|c|c|c|c|c|c|c|}
\hline & & & INOV & & & & \\
\hline & & $\begin{array}{l}\text { Sum of } \\
\text { Squares }\end{array}$ & df & $\begin{array}{l}\text { Mean } \\
\text { Square }\end{array}$ & $\mathbf{F}$ & $\begin{array}{c}\text { P- } \\
\text { Value } \\
\text { Sig. }\end{array}$ & Result \\
\hline & $\begin{array}{l}\text { Between } \\
\text { Groups }\end{array}$ & .000 & 1 & .000 & & & \\
\hline $\begin{array}{l}\text { Sputum_ } \\
\text { smear }\end{array}$ & $\begin{array}{l}\text { Within } \\
\text { Groups }\end{array}$ & .000 & 118 & .000 & & 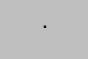 & - \\
\hline & Total & .000 & 119 & & & & \\
\hline & $\begin{array}{l}\text { Between } \\
\text { Groups }\end{array}$ & .133 & 1 & .133 & & & \\
\hline $\begin{array}{l}\text { 2nd mth/ } \\
\text { End of IP }\end{array}$ & $\begin{array}{l}\text { Within } \\
\text { Grouns }\end{array}$ & 15.167 & 118 & .129 & $\begin{array}{c}1.03 \\
7\end{array}$ & .311 & NHA \\
\hline & Total & 15.300 & 119 & & & & \\
\hline & $\begin{array}{l}\text { Between } \\
\text { Groups }\end{array}$ & .075 & 1 & .075 & & & \\
\hline $\begin{array}{l}\text { 6th mth/ } \\
\text { End of CP }\end{array}$ & $\begin{array}{l}\text { Within } \\
\text { Groups }\end{array}$ & 14.517 & 118 & .123 & .610 & .436 & NHA \\
\hline & Total & 14.592 & 119 & & & & \\
\hline & $\begin{array}{l}\text { Between } \\
\text { Groups }\end{array}$ & .033 & 1 & .033 & & & \\
\hline Result & $\begin{array}{l}\text { Within } \\
\text { Groups }\end{array}$ & 15.267 & 118 & .129 & .258 & .613 & NHA \\
\hline & Total & 15.300 & 119 & & & & \\
\hline & & ble 2. Para & netric & Test (ANC & $V A)$ & & \\
\hline $\begin{array}{l}\text { Level of sign } \\
\text { Sig. (P value } \\
\text { Sig. (P value }\end{array}$ & $\begin{array}{l}\text { ficance }=0 . \\
>0.05=\mathrm{Nu} \\
<0.05=\mathrm{Nu}\end{array}$ & $\begin{array}{l}\text { hypothesis } \\
\text { hypothesis }\end{array}$ & $\begin{array}{l}\text { ccepte } \\
\text { ejectec }\end{array}$ & $\begin{array}{l}\text { (NHA) } \\
\text { (NHR) }\end{array}$ & & & \\
\hline
\end{tabular}

Parametric (ANOVA) test sum of squares results were 15.300 , df - 119 , mean squares $0.129, \mathrm{~F}-0.258$, P-value significant - 0.613 . Therefore, there was no difference in the results based on daily regimen and intermittent regimen (Confidence interval $95 \%$ ). There was no significant difference in the final result and sputum conversion at the $2^{\text {nd }}$ month and $6^{\text {th }}$ month based on regimen. Furthermore, another hypothesis had been tested under a specific regimen based on the age and sex of the patient. As a result, the null hypothesis was selected statistically as their P-value was more than 0.05 (level of significance $=0.05$ ). Further, it also represented no significant difference in the sputum conversion at $2^{\text {nd }}$ month and $6^{\text {th }}$ month and outcomes based on age and sex of patient in the specific regimen. Therefore, both the regimens were best suited statistically at a confidence of $95 \%$. However, their suitability could be investigated as per the percentage of cured patients and death cases in each regimen.

Intermittent treatment regimen: There were a total of 120 patients in the study and out of 120 patients, 60 patients were given intermittent regimens under NTEP. 1 patient (1.6 $\%)$ defaulted. $3(5 \%)$ patients died during intermittent treatment regimen, 1 in intensive phase and 2 in the continuation phase. Out of 56 patients who followed up regularly, all patients (93.33\%) were sputum smear-negative at the end of the intensive phase (2 months) and a continuation phase ( 6 months). Out of 56 patients, 1 patient $(1.6 \%)$ remained sputum positive after intensive phase and that patient was given 1 month of extension of intensive phase and the patient became sputum negative after 1 month of extension.

Daily treatment regimen: 60 patients were given daily regimen. One CBNAAT report of one patient $(1.6 \%)$ was suggestive of Mycobacterium tuberculosis detected and rifampicin not detected, three subsequent CBNAAT reports of the same patient suggestive of Mycobacterium tuberculosis not detected, culture for AFB for TB was negative and that patient was not started on antituberculous drugs and regularly followed up as patient needed and at 1 month, 3 months and 6 months follow up and the pt was normal. 3 (5 $\%)$ patients were transferred out for treatment. 1 (1.6\%) pt died in intensive phase only. $1(1.6 \%)$ patient lost to follow up. $1(1.6 \%)$ patient had ZN stain positive, CBNAAT was suggestive of $M$. tuberculosis not detected two first-line LPA reports showed rifampicin sensitive and isoniazid resistance high level and second-line LPA was suggestive of $M$. tuberculosis detected fluoroquinolones and second-line injectables were sensitive, so started on isoniazid $(\mathrm{H})$ mono drug regimen was started before intensive phase. Out of 53 patients who followed up regularly, all patients (88.33\%) were sputum smear-negative at the end of the intensive phase ( 2 months) and a continuation phase (6 months) so declared as cured. Further, transferred out cases were more in daily regimen in comparison with the intermittent regimen. Furthermore, the sex ratio (male to a female) in daily regimen was less than intermittent regimen. With this, it can be assumed that the male patients were high in the intermittent regimen. Therefore, male patients of age group 18 - 40 years have a more recovery efficiency as compared to females.

\section{DISCUSSION}

Tuberculosis (TB) is a communicable disease and one of the top 10 causes of death, worldwide. 10 million people suffered from tuberculosis (TB) worldwide in 2019. But it is a preventable and treatable disease. The 30 high TB burden countries had the majority of new TB cases in 2019. Eight 
countries accounted for two-thirds of the total, with India leading the count. Globally, the incidence of tuberculosis is decreasing at the rate of $2 \%$ per year. Claire J Calderwood et al. meta-analysis, a systematic review found that most patients remained culture positive for 2 weeks of TB treatment. Humankind's fight against TB took a radical turn between 1950 and 1970 with the onslaught of anti-TB drug research that rendered most cases curable. ${ }^{9}$ Tuberculosis was cured in 6 months only with anti-tuberculosis treatment that was developed over 40 years ago and countries with economic resources ceased research for new drugs. Microscopy and culture are bacteriological tests that were used for treatment monitoring. Because of the prolonged excretion of genetic material from dead bacilli, molecular tests have not been used for this purpose, to date. ${ }^{10}$ Karel Styblo of the International Union against TB \& Lung Disease has developed the technical strategy for DOTS in the 1970s and 80s, Styblo refined "a treatment system of checks and balances that provided high cure rates at a cost affordable for most developing countries." This increased the proportion of people cured of TB from $40 \%$ to nearly $80 \%$, costing up to $\$ 10$ per life saved and $\$ 3$ per new infection avoided. ${ }^{11}$ WHO and the World Bank began investigating the potential expansion of this strategy in 2007. To organize antituberculosis efforts, Government of India has taken health initiatives through the National Tuberculosis Elimination Program (NTEP). As per the National Strategic Plan 2012-17, the program has a vision of achieving a "TB free India", and aims to provide universal access to TB control services. ${ }^{12}$ Prospective study by S Bawri, S Ali, [...], and P Baruwa from Lung India: Official Organ of Indian Chest Society showed that overall sputum conversion rate under directly observed treatment, short course (DOTS) chemotherapy was $92 \% .^{13} \mathrm{M}$ Datta et al. Tuber Lung Dis. 1993 Jun. demonstrated a significant finding that even among those who had taken less than $50 \%$ of their treatment, $56 \%$ were bacteriologically negative. ${ }^{14}$ In our study, $71.66 \%$ of patients were in the age group of 18 - 40 years. Sharma et al. in New Delhi, India also found the highest caseload in the age group of $20-60$ years ${ }^{15}$ as this is an economically productive age group. The peak incidence of tuberculosis infection is seen in young age that is 25 - 40 years in non-white adults than in white adults. Thomas E Herchline et al. showed that higher rates of TB infection in young adults ranged from 25 - 40 years. ${ }^{16} 61.06$ $\%$ were male and $38.93 \%$ were female patients in our study. Many other studies have shown that the prevalence and incidence of tuberculosis are higher among males than females. A systematic review and meta-analysis of Katherine C. Horton et al. showed that the TB prevalence was significantly higher among men than women in low- and middle-income countries ${ }^{17}$ age and sex distribution patterns were consistent with a progressive increase in rates of disease by age, and men in National tuberculosis prevalence surveys in Asia by Ikushi Onozaki et al.18 Data from different regions showed a pattern of male excess, but no clear explanation to this finding has been presented. ${ }^{19}$ We have compared sputum smear conversion in daily versus intermittent treatment regimens in new sputum smearpositive pulmonary tuberculosis patients.

Subsequently, in our study, sputum conversion in intermittent regimen was high as compared to daily regimens such as $88.3 \%$ and $93.3 \%$ in daily and intermittent regimen at the end of intensive and continuation phase that is at 2 months and 6 months with $88.3 \%$ out of 53 patients in daily and $93.33 \%$ out of 56 patients in an intermittent regimen. So there was a difference of $5 \%$. So daily regimens and intermittent regimens were equally effective in negative conversion of the sputum at the end of the intensive phase (2 months) and the end of the continuation phase ( 6 months). The difference in sputum conversion between the two regimens was statistically significant $(\mathrm{P}<0.05)$. Due to negative sputum conversion the chances of patient death and infectiousness were reduced. Ha Youn Lee et al. showed a higher culture conversion rate at 2 months of treatment in their study. ${ }^{20}$ Similarly other studies showed that daily regimen and intermittent regimens were equally effective in negative conversion of the sputum smear. ${ }^{21,22}$

In some patient groups, such as those with cavitation on chest X-rays, co-infected with HIV, or with initial resistance to $\mathrm{H}$ in above patients when intermittent treatments were initiated at the starting of a treatment regimen, the likelihood that more failures and amplification of resistance in these three patient groups will occur is somewhat more controversial but some trials have shown just such results. The best way to avoid this is to start a daily regimen if it is not possible at field-level conditions, daily treatment should be given in the intensive phase and three times a week in the continuation phase. But patients infected with HIV should have daily treatments in both phases. Now we are giving daily regimens and in India daily regimens were started in October 2017.

\section{CONCLUSIONS}

In this study, it was concluded that daily and intermittent regimens were equally effective in negative conversion of the sputum smear at the end of an intensive phase and the end of the continuation phase. This reduces the infectiousness and chances of patient death, thus reducing the infection in the community and eventually leading to a decrease in the incidence and prevalence of tuberculosis in society and the country.

\section{Limitations}

In this study, a total of 120 patients were present, and 60 were present in intermittent regimen, out of 60 patients, one patient defaulted, 3 patients died and the remaining 56 patients were regularly followed up and hence these 4 patients were excluded from the study. In the daily treatment regimen, 60 patients were present and out of them 1 patient had resistance, 1 patient died, 1 patient lost to follow up, 3 patients were transferred out for treatment and 1 patient was normal, these 7 patients were excluded from the study, so 53 patients were regularly followed up till cured. All the above patients' conditions were limitations for this study.

Data sharing statement provided by the authors is available with the full text of this article at jemds.com.

Financial or other competing interests: None.

Disclosure forms provided by the authors are available with the full text of this article at jemds.com. 


\section{REFERENCES}

[1] Marten B. A New Theory of Consumptions-More Especially a Phthisis or Consumption of the Lungs. London, England: T. Knaplock. P. 51: "The Original and Essential Cause ... may possibly be some certain Species of Animalcula or wonderfully minute living Creatures, ... P. 79: "It may be therefore very likely, that by an habitual lying in the same Bed with a Consumptive Patient, constantly Eating and Drinking with him, or by very frequently conversing so nearly, as to draw in part of the Breath he emits from his Lungs, a Consumption may be caught by a sound Person 1720. https://en.m.wikipedia.org/wiki/Benjamin_Marten\#cite ref-1

[2] https://lemelson.mit.edu/

[3] https://www.cdc.gov/tb/worldtbday/history.htm

[4] Jensen PA, Lambert LA, Iademarco MF, et al. Guidelines for preventing the transmission of Mycobacterium tuberculosis in health-care settings, 2005. MMWR 2005; 54 (No. $\quad$ RR 17 ). www.cdc.gov/mmwr/preview/mmwrhtml/rr5417a1.ht m?s_cid=rr5417a1_e.

[5] https://www.cdc.gov/tb/educatio/corecurr/pdf/chapte r2.pdf

[6] Caminero JA, ed. Guidelines for Clinical and Operational Management of Drug-Resistant Tuberculosis. Paris, France: International Union against Tuberculosis and Lung Disease 2013.

[7] RNTCP at a Glance, Central TB Division Directorate General of Health Services Ministry of Health and Family welfare (MoHFW), Government of India March 2006.

[8] Training modules (3) for programme managers and medical officers (C) Central TB Division, Ministry of Health and Family Welfare (MoHFW), Government of India 2020.

[9] Caminero JA, ed. Guidelines for Clinical and Operational Management of Drug-Resistant Tuberculosis. Paris, France: International Union Against Tuberculosis and Lung Disease 2013: p. 14.

[10] Caminero JA, ed. Guidelines for Clinical and Operational Management of Drug-Resistant Tuberculosis. Paris, France: International Union Against Tuberculosis and Lung Disease 2013: p. 78.

[11] "TB: Join the DOTS." The economist. May 20, 1995: p. 89.
[12] National Strategic Plan for Tuberculosis Control, 20122017. Central TB Division, Ministry of Health and Family Welfare August 2012.

[13] Bawri S, Ali S, Phukan C, et al. A study of sputum conversion in new smear positive pulmonary tuberculosis cases at the monthly intervals of $1,2 \& 3$ month under directly observed treatment, short course (dots) regimen. Lung India 2008;25(3):118-23.

[14] Datta M, Radhamani MP, Selvaraj R, et al. Critical assessment of smear-positive pulmonary tuberculosis patients after chemotherapy under the district tuberculosis programme. Tuber Lung Dis July 1993;74(3):180-6.

[15] Sharma P, Verma M, Pardeshi G, et al. Epidemiological profile of tuberculosis patients in Delhi, India: a retrospective data analysis from the directly observed treatment short-course (DOTS) center. J Family Med Prim Care 2019;8(10):3388-92.

[16] Herchline TE, Bronze MS, Amorosa JK, et al. Does the incidence of tuberculosis (TB) vary among different age groups? Medscape Jun 04, 2020.

[17] Horton KC, MacPherson P, Houben RMGJ, et al. Sex differences in tuberculosis burden and notifications in low- and middle-income countries: a systematic review and meta-analysis. PLoS Med 2016;13(9):e1002119.

[18] Onozaki I, Law I, Sismanidis C, et al. National tuberculosis prevalence surveys in Asia, 1990-2012: an overview of results and lessons learned. Trop Med Int Health 2015;20(9):1128-45.

[19] Global Tuberculosis Report 2018. World Health Organization 2018: p. 1. https://www.who.int/tb/publications/global_report/gt br2018_main_text_28Feb2019.pdf

[20] Lee HY, Chae KO, Lee CH, et al. Culture conversion rate at 2 months of treatment according to diagnostic methods among patients with culture-positive pulmonary tuberculosis. PLoS One 2014 Aug 8;9(8):e103768.

[21] Bose A, Kalita S, Rose W, et al. Intermittent versus daily therapy for treating tuberculosis in children. Cochrane Database Syst Rev 2014;2014(1):CD007953.

[22] Swapnil MT, Dhamgaye TM. Comparison of daily and intermittent anti tubercular treatment in achieving sputum negativity in newly diagnosed sputum positive pulmonary tuberculosis patients. Int J Med Res Rev 2016;4(10):1744-9. 